\title{
Traditional Knowledge as a Tool for Discussing History and Philosophy of Science in Teacher Education
}

\author{
Wilmo Ernesto Francisco Junior*, Miyuki Yamashita \\ Federal University of Alagoas, Campus Arapiraca, Arapiraca, Brazil \\ Email: *wilmojr@bol.com.br
}

How to cite this paper: Francisco Junior, W. E., \& Yamashita, M. (2018). Traditional Knowledge as a Tool for Discussing History and Philosophy of Science in Teacher Education. Creative Education, 9, 567-574. https://doi.org/10.4236/ce.2018.94040

Received: November 9, 2017

Accepted: April 9, 2018

Published: April 12, 2018

Copyright (c) 2018 by authors and Scientific Research Publishing Inc. This work is licensed under the Creative Commons Attribution International License (CC BY 4.0).

http://creativecommons.org/licenses/by/4.0/

\section{(c) (i) Open Access}

\begin{abstract}
Increasingly, issues with to multiculturalism have crossed into science classrooms. In this way, traditional knowledge has been pointed out as a pathway towards placing value on the culture of distinct social groups and thus addressing sociocultural dimensions of science. Taking this into account, this study proposed an approach for inserting historical, philosophical and sociocultural themes from traditional knowledge. This proposal was developed among chemistry students and it was characterized as a small research project. The students needed to identify traditional knowledge relating to chemistry in their community and to gather data on it. The students' reports showed characteristics of scientific literacy, specially related to sociocultural dimension of the science.
\end{abstract}

\section{Keywords}

Chemistry Education, Scientific Literacy, Teacher Education

\section{Introduction}

Increasingly, issues associated with multiculturalism have crossed into science classrooms. Traditional knowledge has been pointed out as a pathway towards placing value on the culture of distinct social groups and thus addressing the historical, philosophical and sociocultural dimensions of science, besides fostering students' open-mindedness and learning (Aikenhead \& Jegede, 1999; Chassot, 2008; Austin \& Hickey, 2011). Moreover, discussion of traditional knowledge in science classrooms can contribute towards changes to relationships of domination that have been built in different sociocultural circumstances. According to Arroyo (2012): 
These social groups show that conceptions and educational practices that are thought to educate them and civilize them are conditioned by ways of thinking about them (...) and subordinating them. Pedagogical theories do not apply conceptions or epistemologies from outside of the civilized and civilizing centers, but conceptions that are minted within the concreteness of powerlknowledge colonization (2012, p. 11).

However, this debate is not new in the field of education. The Brazilian educator Paulo Freire signaled this in proposing a dialogical method "constituted by and organized from the students' view of the world, in which their own generative themes are found" (Freire, 2005a: p. 109). In this first stage of the dialogical method, meaningful themes from phenomena, situations or events of relevance to the students' sociocultural life are investigated and identified.

The importance of traditional knowledge can be explained by the need for more critical understanding of modern societies and the need to restore human values, so as to build conditions of life that are more equitable, among other reasons. Following Paulo Freire (2005b: pp. 25-26):

One of the central features of the domination process is cultural invasion of the dominant over the oppressed. Thus, cultural invasion is fundamental because it is concerned with power (...). When we look at experiences in colonized countries, including Brazil, it is possible to see barbarity, disputation and colonizing behavior (...). Its presence can be perceived exactly in everything and in everyone. This war is waged by a domineering colonialist and imperialist government to crumble the cultural identity of people and groups within the dominated class, so that material expropriation from the dominated people can more easily be achieved (2005b, pp. 25-26).

From this point of view, students can develop intercultural understanding through learning to value their own cultures, languages and beliefs. They will come to understand how personal, group and national identities are shaped, along with the variable and changing nature of culture. Hence, it is important to create and implement pedagogical practices that consider other social groups, given that they come to the educational establishment with different experiences and ways of thinking and acting regarding their contexts and social relationships. At the same time, it is important to recognize that the role of science classes is to promote understanding of scientific concepts and theories. This requires reinvention of theories and pedagogical practices for thinking about education, knowledge and teaching.

It is fair to assume that use of the history and philosophy of science cannot be restricted to teaching scientific concepts. It can especially contribute towards debates on science and technological developments and their implications for society. Taking into account that the history of science can contribute towards discussions about technological and scientific development in association with social issues, the present study proposed an approach for inserting historical, philosophical and sociocultural themes from traditional knowledge, based 
upon the following question: Can traditional knowledge foster the comprehension about science? The main purpose was to investigate the appropriation of elements of scientific literacy from a small research project developed by students to identify traditional knowledge in their social communities.

\section{Methodological Procedures}

This study can be characterized as action research. According to Trip (2005), this methodology can be seen as a strategy for developing teachers and students so that they can use their research to improve teaching and consequently learning. Trip (2005) also pointed out characteristics that are included in action research: it should be innovative, continuous, strategically proactive, participatory, interventionist, questioning, deliberate, documented, understood and disseminated. Moreover, well-established research techniques should be used to address actions that entail improvements in practice.

The research was developed as part of the activities in classes on the history of chemistry at a Brazilian federal university in the years 2013 and 2014. In these two years, 49 chemistry students had been enrolled in that discipline and all of them collaborated voluntarily in this study. As a first step, an investigation project was presented to be developed by the students as a final task. In this project, the students would need to identify traditional knowledge relating to chemistry that existed in their community. Then, the students would need to gather data on this knowledge by means of a field investigation. For this, they conducted interviews with a view to finding out about the topic, and about how and when people learned it. This field research lasted around two months and was carried out in groups of two or three students. In the meantime, theoretical reference points regarding the history and philosophy of science were discussed.

The results from this field research were presented by means of a written report and a poster during a mini-conference at the university. The reports needed to be written based on the theories of history and philosophy that had been discussed. In total, 23 reports were produced. These reports were read and gathered by similarity generating excerpts that could be associated with elements of scientific literacy. This analysis followed qualitative content analysis principles (Bardin, 2006). This analysis allowed to identify indicators relating to three issues: the nature of comprehension of science, scientific language and socioscientific issues (Santos, 2007). These indicators were assembled in categories that can be considered to form a representation of the students' scientific literacy.

\section{Results and Discussion}

Some indicators of scientific literacy were identified from reports based on Silva (2007), which distinguished three important characteristics: the nature of comprehension of science; scientific language and socioscientific issues. From this, no indicators of scientific literacy were identified in 5 of the 23 reports. In these 
cases, traditional knowledge was only described and there were no explanations. Although descriptions are a necessary characteristic of scientific reports, they are insufficient for data interpretation if there are no explanations, arguments and comparisons. The other reports presented at least one indicator.

With regard to the nature of comprehension of science, descriptions and comparisons between science and traditional knowledge exist. Knowledge of science was also recognized as being human, social, mutable and influenced by historical context and as having social implications/applications (Table 1).

Most of the texts contextualized the historical process of construction of science, and highlighted the influence of social issues and social roles. The presence of theoretical reference points that had been studied during the course was another important characteristic.

"We noted the social context of the production and transmission of knowledge. For instance, the way in which a person learned specific knowledge is in accordance with the dynamics of the scientific community, as presented by Kuhn, in which a group of scientists shares a tradition of doing science, including hierarchy (...)."

The students also established comparisons founded in historical and social contexts.

"Scientific knowledge is not unquestionable and it can at any time undergo changes such that it loses its supposed veracity by the time one argument overcomes the previous one. In this manner, it cannot live with contradictions. Furthermore, scientific knowledge can be an irrefutable true in one historical period and a great mistake in another. In general, new knowledge can replace or modify an existing paradigm. Thus, for knowledge to be considered scientific, certain steps are necessary (...) Among these is acceptance by the scientific community."

"Scientific knowledge is systematic, factual and nearly exact, while cultural knowledge has usually been qualified as subjective and inexact. The rupture between scientific and cultural knowledge is an inheritance of the scientific revolution. Even within postmodernity, in which certainties are relativized, along with the very notion of what the truth is, science does not lose its central role within culture. Despite the differences between these two ways of knowing things, it is necessary to recognize that the primacy of science over traditional knowledge results from the cultural centralism that has invalidated knowledge that was

Table 1. Indicators of scientific literacy regarding the nature of comprehension of science.

\begin{tabular}{ccccc}
\hline $\begin{array}{c}\text { Literacy } \\
\text { indicator }\end{array}$ & $\begin{array}{c}\text { Science as } \\
\text { human and } \\
\text { social activity }\end{array}$ & $\begin{array}{c}\text { Science as human } \\
\text { and social activity }\end{array}$ & $\begin{array}{c}\text { Mutability of } \\
\text { scientific } \\
\text { knowledge }\end{array}$ & $\begin{array}{c}\text { Social } \\
\text { applica-tions/implications } \\
\text { of science }\end{array}$ \\
\hline Reports & 17 & 14 & 14 & 14 \\
\hline
\end{tabular}

Source: Research data. 
constructed from points of view that were not scientific. Two examples in two different environments. a classroom and a medical office. In the classroom, teachers dominate knowledge in a way that clashes with students conceptions, their world view and culture. Fortunately, nowadays, these different canonical areas of education and healthcare have tried to integrate cultural knowledge, which is not seen as opposite, but just different."

In these reports, connections between scientific and cultural knowledge and relationships from particular thematic areas, especially factual knowledge as opposed to ideas relating to values, attitudes, beliefs and identity, can be identified. As stated by students, cultural knowledge has usually been qualified as inferior than scientific knowledge. However, considering the historical construction, this sort of knowledge is also systematic, factual and nearly exact. Construction of common ground between scientific knowledge and cultural knowledge, as well as recognition of their differences, may have a fundamental role in inserting and broadening elements of the history and sociology of science. Freire argued that:

In problem-posing education, people develop their power to critically perceive the way they exist in the world with which and in which they find themselves, they come to see the world not as a static reality, but as a reality in process, in transformation. (...). Hence, the teacher-student and the student-teachers reflect simultaneously on themselves and the world without dichotomizing this reflection from action, and thus establish an authentic form of thought and action (2005a, p. 83).

In this particular case, involvement in an action-research task that sought not to dichotomize reflections from action may have been a determining factor for appearance of indicators about the nature of comprehension of science. Brandt (2007) proposed that through identifying the common ground that exists, educators can make attempts to work across any perceived differences, thus breaking down the divides and reconstructing the relationship between science and cultural knowledge. Given that scientific knowledge takes on an indispensable role in science classrooms, the dialogue between scientific and traditional knowledge seems to be an interesting pathway towards learning some elements within the history and philosophy of science.

Concerning scientific language, four categories of indicators were identified: use of reports in a scientific genre, use of scientific terminology and symbols, explanations and argumentation (Table 2). The students were asked to present scientific reports in a specific genre. However, less than half of the reports (10) were presented in accordance with this genre, which reveals that they had difficulties in

Table 2. Indicators of scientific literacy about science language.

\begin{tabular}{ccccc}
\hline $\begin{array}{c}\text { Literacy } \\
\text { indicator }\end{array}$ & $\begin{array}{c}\text { Use of reports in a } \\
\text { scientific genre }\end{array}$ & $\begin{array}{c}\text { Use of scientific } \\
\text { terminology and } \\
\text { symbols }\end{array}$ & Explanation & Argumentation \\
\hline Reports & 10 & 12 & 12 & 12 \\
\hline
\end{tabular}

Source: Research data. 
doing this. Use of a scientific genre requires a conscious process that depends on appropriation of scientific language (Mortimer, 1999).

Furthermore, this genre is not commonly used, which may cause difficulties in producing it. Despite this difficulty, explanations and argumentation were observed in some reports.

"We can highlight that Kuhn's thinking shows how important it is for the scientific community to influence and determine what can be considered science. From this point of view, traditional knowledge would be scientific if accepted by the community."

In this excerpt, explanations about the role of the scientific community in accepting or rejecting a theory can be noted. Furthermore, the argument that can be observed is that if traditional knowledge were to pass through the same validation steps, it would become scientific knowledge. Argumentation and discourse become central elements of education, particularly in science education because of the key role of argumentation in scientific communities.

According to Lemke (1990), learning science requires appropriation of scientific discourse, including describing, comparing and concluding. Thus, the presence of explanations and argumentation reveals important evidence for scientific literacy. Moreover, it shows characteristics of critical thinking.

An effective science education process not only requires active involvement on the part of students in terms of scientific investigation, but also contributes towards development of discursive practices that enable students to apply their understandings of science to personal decision-making. These discursive practices, which include evaluating evidence, assessing alternatives, establishing the validity of scientific claims and addressing counterevidence, constitute scientific argumentation (Driver et al., 2000).

With regard to indicators of socioscientific issues in the reports, most of them (16 reports) related to discussion between science and non-science, in this case scientific and traditional knowledge respectively. Some students also pointed out the social validity of traditional knowledge (14 reports) and its importance for local culture (10 reports) (Table 3 ).

"Through these considerations, we have perceived the importance of cultural knowledge in the social medium. It is fair to consider that it was through traditional knowledge that many people or civilizations determined important practices and developed objects for use in their daily lives and, sometimes, to obtain financial sustainability. According to Kuhn, knowledge elaborated by different cultures would not be better or worse, or more or less correct than that of other

Table 3. Indicators of scientific literacy about socioscientific issues.

\begin{tabular}{ccccc}
\hline $\begin{array}{c}\text { Literacy } \\
\text { indicator }\end{array}$ & $\begin{array}{c}\text { Discussion of science } \\
\text { versus non-science }\end{array}$ & Social validity & $\begin{array}{c}\text { Importance of } \\
\text { knowledge for } \\
\text { local culture }\end{array}$ & $\begin{array}{c}\text { Knowledge to } \\
\text { support teaching }\end{array}$ \\
\hline Reports & 16 & 14 & 10 & 02 \\
\hline
\end{tabular}

Source: Research data. 
cultures, since such knowledge relates to human constructions under specific conditions, such as distinct societies and times."

"Soap manufacturing represents a social reflection of the people and of the community, through supplying a necessity of life, for daily use, for economy and even for business, through sales. Thus, soap manufacturing has contributed towards these families incomes."

Autonomous thinking and the capability to intertwine social issues with theory and practice can be seen as indicators of scientific literacy (Santos, 2007). Doubtlessly, the students did not necessarily develop these abilities from this work. At the same time, the relationships established from some specific points of view, like those relating to thinkers within the history and philosophy of science, can be seen as positive, because this process is intrinsically associated with learning, which was the main purpose of this proposal.

Regardless of the ongoing dominance of scientific knowledge, the students also presented arguments for use of traditional knowledge as a teaching tool. This was in accordance with studies grounded within a perspective of multiculturalism. However, even if this possibility is acknowledged, it is important to note that the role of science classrooms is to teach science.

\section{Final Remarks}

Firstly, it is important to highlight the limitations of the present analysis about what would constitute a scientifically literate individual, given that this analysis only considered texts, rather than wide-ranging participation in society. Nonetheless, some indicators of scientific literacy were identified such as autonomous thinking and the capability to intertwine social issues with theory and practice. These two aspects are seen as indicators of scientific literacy (Santos, 2007) and they can be observed when students pose problems from their scholarly knowledge in relation to social and economic issues from investigations. Most of the students were able to embrace different forms of cultural knowledge and promote explicit and enquiring discussions on values, attitudes, beliefs and identity that were associated with both knowledge domains.

Thus, the outcomes showed that the students developed indicators of scientific literacy as a deeper reflection about the implications of science. This will be important for these students in future pedagogical practice concerned with cultural specificities in the classroom. Their participation in an investigative process was probably one of the determining factors, since this can be understood as a thematic investigation. As Freire pointed out (2005a, p. 109):

Every thematic investigation that deepens historical awareness is thus really educational, while all authentic education investigates thinking. The more that educators and the people investigate the people's thinking, and are thus jointly educated, the more that they will continue to investigate.

Hence, this study signaled the potential of thematic investigations concerned with traditional knowledge in relation to chemistry as a possibility for promoting a learning process within the history, philosophy and sociology of science. 


\section{References}

Aikenhead, G., \& Jegede, O. (1999). Cross-Cultural Science Education: A Cognitive Explanation of a Cultural Phenomenon. Journal of Research in Science Teaching, 36, 269-287.

Arroyo, M. G. (2012). Outros sujeitos, outraspedagogias [Others Subjects, another Pedagogy]. Petrópolis: Vozes.

Austin, J., \& Hickey, A. (2011). Incorporating Indigenous Knowledge into the Curriculum: Responses of Science Teacher Educators. The International Journal of Science in Society, 2, 139-152.

Bardin, L. (2006). Análise de Conteúdo [Content Analysis]. Lisboa: Edições.

Brandt, C. (2007). Epistemology and Temporal/Spatial Orders in Science Education: A respOnse to Aikenhead \& Ogawa's: Indigenous Knowledge and Science Revisited. Cultural Studies of Science Education, 2, 539-620.

Chassot, A. (2008). Haciendoeducaciónencienciasenlosestudios de Pedagogía con la inclusión de saberespopularesen el currículum [Making Science Education within the Syllabi of Pedagogy, with the Inclusion of Popular Knowledge in the Curriculum]. EducaciónQuímica, 18, 12-15.

Driver, R., Newton, P., \& Osborne, J. (2000). Establishing the Norms of Scientific Argumentation in Classrooms. Science Education, 84, 287-312.

Freire, P. (2005a). Pedagogy of the Oppressed(30th Anniversary Edition). New York: The Continuum International Publishing Group.

Freire, P. (2005b). Pedagogia da Tolerância [Pedagogy of the Tolerance]. São Paulo: UNESP.

Lemke, J. L. (1990). Talking Science: Language, Learning, and Values. New Jersey: Arblex Publishing Corporation.

Mortimer, E. F. (1999). Sobrechamas e cristais: A linguagemcotidiana, a linguagemcientífica e o ensino de ciências [About Flames and Crystals: Everyday Language, Scientific Language and Science Teaching]. In A. Chassot, \& R. J. Oliveira (Eds.), Ciência, Ética e Culturana Educação [Science, Ethics and Culture in Education] (pp. 99-118). São Leopoldo: Editora Unisinos.

Santos, W. L. P. (2007). Educaçãocientíficanaperspectiva de letramentocomoprática social: funções, princípios e desafios' [Scientific Education in the Perspective of Literacy as Social Practice: Functions, Principles and Challenges]. Revista Brasileira de Educação, 12, 474-492.

Trip, D. (2005). Action Research: A Methodological Introduction. Research and Education, 31, 443-466. 